\title{
Assessment of an Emergency Medicine System for Radiation Accidents in Korea: A State Survey of the Workers Involved the Medical Response to Radiation Accidents
}

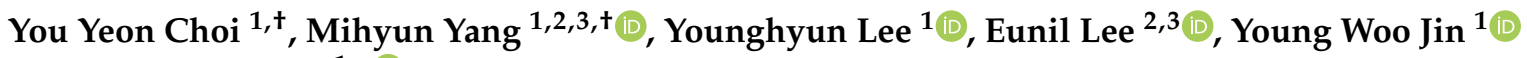 \\ and Ki Moon Seong ${ }^{1, *(D)}$ \\ 1 National Radiation Emergency Medical Center (NREMC), Korea Institute of Radiological \& Medical \\ Sciences (KIRAMS), Seoul 01812, Korea; c9640@kirams.re.kr (Y.Y.C.); mhy@kirams.re.kr (M.Y.); \\ ylee@kirams.re.kr (Y.L.); ywjin@kirams.re.kr (Y.W.J.) \\ 2 Department of Environmental and Occupational Health, Graduate School of Public Health, Korea University, \\ Seoul 02841, Korea; eunil@Korea.ac.kr \\ 3 Department of Preventive Medicine, College of Medicine, Korea University, Seoul 02841, Korea \\ * Correspondence: skmhanul@kirams.re.kr \\ + These authors equally contributed to this work.
}

check for updates

Citation: Choi, Y.Y.; Yang, M.; Lee, Y.; Lee, E.; Jin, Y.W.; Seong, K.M. Assessment of an Emergency Medicine System for Radiation Accidents in Korea: A State Survey of the Workers Involved the Medical Response to Radiation Accidents. Int. J. Environ. Res. Public Health 2021, 18, 2458. https://doi.org/10.3390/ ijerph18052458

Academic Editors:

Alberto Ruano-Ravina and Paul B. Tchounwou

Received: 2 December 2020

Accepted: 24 February 2021

Published: 2 March 2021

Publisher's Note: MDPI stays neutral with regard to jurisdictional claims in published maps and institutional affiliations.

Copyright: (c) 2021 by the authors. Licensee MDPI, Basel, Switzerland. This article is an open access article distributed under the terms and conditions of the Creative Commons Attribution (CC BY) license (https:// creativecommons.org/licenses/by/ $4.0 /)$.

\begin{abstract}
Radiation emergency medicine systems are operated around the world to provide special care for the injured that require immediate medical attention in accidents. The objective of this survey was to evaluate people's perception of those who design the emergency medical plan for radiation accidents and those who supervise it in Korea. A questionnaire survey was conducted on the people involved in a regulatory system for medical response in a radiation emergency. Of 150 survey recipients, 133 (88.7\%) completed the survey, including 92 workers and 41 inspectors. The respondents expressed the view that the national emergency medical plan is prepared above the average level using a Likert-style scale of 1 to 5 (mean $=3.55$, SD $=0.74$ ). Interestingly, using the Mann-Whitney U test, it could be shown that inspectors evaluated the emergency medical system for radiation accidents more strictly in all of the questions than the licensee workers, especially on radiation medical emergency preparedness $(p=0.004)$ and the governmental regulatory policy for radiation safety ( $p=0.007$ ). For a more efficient system of radiation emergency medicine, licensee workers prioritized the workforce, whereas inspectors favored laws and regulations for safety. The survey results show different perspectives between inspectors and licensee workers, which stem from the actual properties of each occupational role in the regulatory system for radiation medical emergency. These data could be utilized for communication and interaction with relevant people to improve the medical response preparedness against radiation accidents.
\end{abstract}

Keywords: emergency medicine system; radiation; licensee workers; inspectors; occupational role; regulatory system

\section{Introduction}

After the Fukushima nuclear power plant (NPP) accident in Japan in March 2011, the public was overwhelmed by severe anxiety about radiation exposure in Korea, which resulted in temporary closures of schools, massive selling of masks against radioactive dust, and a higher distrust of the health and safety of agricultural and marine products from Japan $[1,2]$. The people seriously considered the radiation safety issue due to the geographical proximity to the accident site and the tens of nuclear power plants and industrial applications in the Korean peninsula [3]. The people demanded the government prepare a consolidated regulatory system focused on radiation safety. The roles and responsibilities of the Nuclear Safety and Security Commission (NSSC), a governmental organization for nuclear safety and regulation in Korea similar to the United States Nuclear Regulatory Commission (U.S NRC), have been intensified to oversee affairs regarding 
the radiation emergency preparedness and response, including the medical emergency response system $[4,5]$. A medical response network was constructed with 24 hospitals for radiation emergencies in Korea. More than 600 medical staff elements and first responders have been educated and trained for various kinds of radiation emergencies. The role of local governments in Korea for the radiation emergency medicine system is to implement the protective actions based on providing assistance for the medical system, including the support of emergency service systems for patient transfer, contamination screening and decontamination of residents before and after moving into shelter, psychological counseling, and potassium iodine distribution and monitoring of side effects. As a previously reported study showed, the network of emergency medicine will work more efficiently for those injured in a crisis of radiation when the initial medical response is appropriate at the sites of accidents in radiation facilities [6].

As stated in the legal Article 45 of the Act on Measures for the Protection of Radiation Disasters in Korea, all nuclear licensees, such as companies and institutes having nuclear or radiation facilities, should establish medical preparedness plans for protection and human care in a radiation emergency, and implement drills at their facilities following the plan. This is in accordance with the international recommendation for safety requirements assigned by International Atomic Energy Agency (IAEA) as emergency preparedness categories I, II, III, and IV [7]. The emergency medicine plan for radiation facilities also needs to be examined and inspected from the design to the execution of emergency drills. To become more efficient against radiation accidents, the plan needs to be continually examined and supplemented. As entrusted by the NSSC since 2015, a revision and inspection of the radiation emergency medical plan has been legally performed by the specialists of the National Radiation Emergency Medical Center (NREMC), which provides specialized training courses for the first responders and medical staff in a radiation emergency, such as the Radiation Emergency Assistance Center/Training Site (REAC/TS) [8].

To strengthen the medical care for worker victims of occupational radiation exposure due to accidents, a unique regulatory system for radiation emergency medicine was legally introduced to all of the companies and institutes with nuclear/radiation facilities in Korea. They should prepare the emergency medicine plan for nuclear/radiological accidents, including the rescue of the injured, first aid, and transfer of patients to hospitals. The plan should be designed taking into account the scale, structure, and number of workers of each facility, according to references such as the IAEA guidance $[9,10]$. Specialists should review the medical response plan for radiation emergencies and regularly inspect the implementation of the plan at on-site facilities, accompanying every radiation emergency drill. Inspectors and licensee workers together have developed and complemented an emergency medicine system for radiation accidents through many assessments and discussions, and this communication is thought to be essential for the successful design of a plan. This is a unique regulatory system for medical responses to radiation emergencies that could not be found in other countries. Moreover, there is no internationally stipulated standard to ensure a prompt and efficient medical intervention for radiation accidents. Thus, this plan could be the basis for radiation safety regulation by other national authorities.

The companies and institutes with radiation facilities should prepare their own emergency medical plans, which should be examined by law. The NREMC has investigated the individual emergency plans for each facility and assessed whether they could be appropriately executed under a radiation emergency. The emergency medicine plans are not identical, and can be very complicated, depending on the scale of the facilities, the structure of the building, and the number of workers. This survey aimed to evaluate the perception of people involved in the execution and examination of the emergency plan of medical preparedness for a radiation emergency. This kind of survey study of the perception of societal issues is usefully applied to investigate the gap-filling of perspectives that are different between interested stakeholders, including the public [11,12]. Previous research about the social anxiety and poor quality of life after the NPP accident by Japanese researchers reflect concerns about exposure to radiation $[13,14]$. Communication with 
the perception data is considered as an effective way to solve the problem of knowledge deficiency towards formulating the public's understanding.

\section{Materials and Methods}

\subsection{Survey Methods}

A questionnaire (Appendix A) was devised by the authors and validated for this study by a statistician, epidemiologist, and health physicist. It was pilot tested by a small group of people, including medical staff, health physicists, and administrators in emergency medical planning and then modified before execution as a large-scale survey. The questionnaire consisted of 18 questions, including 6 questions addressing the perception of the radiation emergency medicine system, 5 questions assessing the knowledge of radiation, and 7 questions addressing respondents' personal information (i.e., sex, age, academic degree, affiliation, occupational role, career periods, and relevance to medical emergencies). A questionnaire survey was conducted on the people involved in the radiation medical emergency plan. Some are licensee workers preparing the emergency plan in each organization, such as companies and institutes with nuclear or radiation facilities, not hospitals in the radiation emergency network, and the others are specialists (inspectors) that examine and evaluate the plan. It was administered to the participants during a workshop for medical preparedness for radiation emergencies in December 2019. Some responses were collected at the workshop and the others were delivered by e-mail as a scanned file to increase the response rate for the survey. The responses were measured using a Likert-style scale of 1 to 5 . The responses were anonymous and would not influence the performance in a specific study course. This study was approved by the institutional review board (IRB: KIRAMS 2020-04-009) of the Korea Institute of Radiological and Medical Sciences and conducted following the Declaration of Helsinki.

\subsection{Statistical Analysis}

Statistical analysis was performed using SPSS software (version 23; SPSS Inc., Chicago, IL, USA). Univariate and multivariate linear regression was performed to explore variables related to the answer to "Do you agree that the national plan of emergency medicine is well-prepared for nuclear or radiation accidents?" A Mann-Whitney U test was used to compare the question \#8-\#11 score of inspectors with licensee workers. Pearson's chisquare analysis was used to analyze the difference in the proportion of medical emergency work between inspectors and licensee workers. A $p$-value $<0.05$ was considered to be statistically significant.

\section{Results}

\subsection{General Characteristics of Respondents}

One-hundred thirty-three of the participants in the workshop for radiation emergency medicine replied to the survey; 150 questionnaire sheets were distributed $(88.7 \%$ collection rate). Radiation emergency medicine (REM) staff in our survey of the workshop are representative workers entrusted by each company and institute with the license. In total, 689 persons have been enrolled as REM staff and affiliated with various companies and institutes, including a nuclear power plant, nuclear fuel manufacturing company, largescale irradiation facility, radio waste disposal company, and R\&D institute in Korea (as of 19.03.31). We believed that the survey results showed the representative opinion of the REM staff, considering the response ratio (133/689). Our study subjects consist of workers with various occupations with different affiliations. They are radiation safety officers, administrators, medical doctors, and medical researchers, including health physicists, radiation biologists, and medical specialists. Approximately $70 \%$ of the respondents were radiation workers affiliated with companies and institutes undergoing a revision and inspection of the emergency medicine plan, and $43 \%$ of them worked for a nuclear power company. Based on the score of five questions assessing the knowledge of radiation, they had the basic knowledge necessary for radiation safety, given that $90.4 \%$ answered more 
than three questions correctly. Over half of them had more than six years of experience with radiation emergency preparedness (Table 1).

Table 1. Participants' socio-demographic characteristics.

\begin{tabular}{|c|c|c|c|c|c|c|}
\hline \multirow{3}{*}{ Factor } & \multirow{2}{*}{\multicolumn{2}{|c|}{ Total }} & \multicolumn{4}{|c|}{ Occupational Role } \\
\hline & & & \multicolumn{2}{|c|}{ Licensee Worker } & \multicolumn{2}{|c|}{ Inspector } \\
\hline & $\begin{array}{l}\text { Frequency } \\
\text { (Persons) }\end{array}$ & Percentage (\%) & $\begin{array}{l}\text { Frequency } \\
\text { (Persons) }\end{array}$ & Percentage (\%) & $\begin{array}{l}\text { Frequency } \\
\text { (Persons) }\end{array}$ & Percentage (\%) \\
\hline & 133 & 100 & 92 & 69.2 & 41 & 30.8 \\
\hline \multicolumn{7}{|l|}{ Sex } \\
\hline Male & 100 & 75.2 & 77 & 83.7 & 23 & 56.1 \\
\hline Female & 33 & 24.8 & 15 & 16.3 & 18 & 43.9 \\
\hline \multicolumn{7}{|l|}{ Age (years) } \\
\hline $20 \sim 29$ & 9 & 6.8 & 4 & 4.3 & 5 & 12.2 \\
\hline $30 \sim 39$ & 61 & 45.9 & 37 & 40.2 & 24 & 58.5 \\
\hline $40 \sim 49$ & 35 & 26.3 & 27 & 29.3 & 8 & 19.5 \\
\hline $50 \sim 69$ & 28 & 21.1 & 24 & 26.1 & 4 & 9.8 \\
\hline \multicolumn{7}{|l|}{ Education } \\
\hline High school & 2 & 1.5 & 2 & 2.2 & 0 & 0.0 \\
\hline $\begin{array}{c}\text { Bachelor's } \\
\text { degree }\end{array}$ & 98 & 73.7 & 80 & 87.0 & 18 & 43.9 \\
\hline $\begin{array}{c}\text { Master's } \\
\text { degree }\end{array}$ & 21 & 15.8 & 9 & 9.8 & 12 & 29.3 \\
\hline $\begin{array}{c}\text { Doctorate } \\
\text { degree }\end{array}$ & 12 & 9.0 & 1 & 1.1 & 11 & 26.8 \\
\hline \multicolumn{7}{|l|}{ Affiliation } \\
\hline $\begin{array}{l}\text { Nuclear power } \\
\text { generation }\end{array}$ & 58 & 43.6 & 58 & 63.0 & 0 & 0.0 \\
\hline $\begin{array}{l}\text { Nuclear fuel } \\
\text { manufacturing }\end{array}$ & 10 & 7.5 & 10 & 10.9 & 0 & 0.0 \\
\hline $\begin{array}{c}\text { Large-scale } \\
\text { irradiation } \\
\text { facility }\end{array}$ & 2 & 1.5 & 2 & 2.2 & 0 & 0.0 \\
\hline $\begin{array}{c}\text { Radiation } \\
\text { waste disposal }\end{array}$ & 1 & 0.8 & 1 & 1.1 & 0 & 0.0 \\
\hline $\begin{array}{l}\text { Research and } \\
\text { development } \\
\text { institutions } \\
\text { Period of } \\
\text { career (years) }\end{array}$ & 62 & 46.6 & 21 & 22.8 & 41 & 100.0 \\
\hline $\begin{array}{c}\text { Less than } 1 \\
\text { year }\end{array}$ & 13 & 9.8 & 9 & 9.8 & 4 & 9.8 \\
\hline $1 \sim 5$ & 52 & 39.1 & 33 & 35.9 & 19 & 46.3 \\
\hline $6 \sim 10$ & 19 & 14.3 & 13 & 14.1 & 6 & 14.6 \\
\hline 11 15 & 17 & 12.8 & 8 & 8.7 & 9 & 22.0 \\
\hline over 16 & 32 & 24.1 & 29 & 31.5 & 3 & 7.3 \\
\hline \multicolumn{7}{|c|}{$\begin{array}{c}\text { Job proportion in medical } \\
\text { emergencies }(\%)\end{array}$} \\
\hline Less than 20 & 77 & 57.9 & 68 & 73.9 & 9 & 22.0 \\
\hline $21 \sim 40$ & 16 & 12.0 & 12 & 13.0 & 4 & 9.8 \\
\hline $41 \sim 60$ & 10 & 7.5 & 7 & 7.6 & 3 & 7.3 \\
\hline $61-80$ & 10 & 7.5 & 4 & 4.3 & 6 & 14.6 \\
\hline $81 \sim 100$ & 20 & 15.0 & 1 & 1.1 & 19 & 46.3 \\
\hline
\end{tabular}




\subsection{Factors Associated with the Evaluation of the Status of Radiation Medical Emergency Preparedness}

People related to medical preparedness of radiation emergencies were asked to evaluate the medical preparedness status of the radiation emergency plan, and the responses were investigated depending on the respondents' characteristics (Table 1). They perceived that the national emergency medicine plan is prepared over the average level (mean $=3.55$, $\mathrm{SD}=0.74$, Table 2). To examine what factors were associated with the evaluation of radiation emergency medicine, we analyzed the surveyed responses using univariate and multivariate linear regression. Female responders, inspectors, a career period of more than 16 years, and a job proportion in emergency medicine of over $80 \%$ were tightly associated with the evaluation results for national radiation emergency medicine (Table 2). Moreover, occupational roles, licensee workers, or inspectors were significantly associated with the evaluation results after controlling for sex, occupational role, career period, and job proportion in emergency medicine $(B=-0.356, p=0.043)$. None of the other variables were statistically correlated with evaluation results.

Table 2. Linear regression analyses of the factors associated with responses to the question, "Do you agree that the national plan of emergency medicine is well-prepared for nuclear or radiation accidents?".

\begin{tabular}{|c|c|c|c|c|c|c|}
\hline \multirow{2}{*}{ Factor } & \multirow{2}{*}{ Number } & \multirow{2}{*}{$\begin{array}{c}\text { Mean (SD) } \\
\text { of Response }\end{array}$} & \multicolumn{2}{|c|}{ Univariate } & \multicolumn{2}{|c|}{ Multivariate } \\
\hline & & & ${ }^{\Psi}$ B $(95 \% \mathrm{Cl})$ & $p$-Value & ${ }^{\Psi}$ B $(95 \% \mathrm{Cl})$ & $p$-Value \\
\hline $\begin{array}{l}\text { Total } \\
\text { Sex }\end{array}$ & 133 & $3.55(0.74)$ & & & & \\
\hline Male & 100 & $3.65(0.72)$ & Reference & & & \\
\hline Female & 33 & $\begin{array}{c}3.24 \\
(0.75)\end{array}$ & $\begin{array}{l}-0.408 \\
(-0.695 \\
-0.120)\end{array}$ & $0.006^{*}$ & $\begin{array}{c}-0.169 \\
(-0.538,0.201)\end{array}$ & 0.368 \\
\hline \multicolumn{7}{|l|}{ Age (years) } \\
\hline $20 \sim 29$ & 9 & $3.78(0.44)$ & Reference & & & \\
\hline $30 \sim 39$ & 61 & $3.36(0.58)$ & $\begin{array}{c}-0.417 \\
(-0.932,0.098)\end{array}$ & 0.111 & $\begin{array}{c}-0.451 \\
(-0.968,0.066)\end{array}$ & 0.087 \\
\hline $40 \sim 49$ & 35 & $3.63(0.97)$ & $\begin{array}{c}-0.149 \\
(-0.688,0.390\end{array}$ & 0.585 & $\begin{array}{c}-0.338 \\
(-0.929,0.252)\end{array}$ & 0.259 \\
\hline $50 \sim 69$ & 28 & $3.79(0.74)$ & $\begin{array}{c}0.008 \\
(-0.545,0.560)\end{array}$ & 0.977 & $\begin{array}{c}-0.398 \\
(-1.039,0.243)\end{array}$ & 0.221 \\
\hline \multicolumn{7}{|l|}{ Education } \\
\hline High school & 2 & $3.5(0.71)$ & Reference & & & \\
\hline $\begin{array}{l}\text { Bachelor's } \\
\text { degree }\end{array}$ & 98 & $3.63(0.72)$ & $\begin{array}{c}0.133 \\
(-0.908,1.173)\end{array}$ & 0.801 & $\begin{array}{c}0.611 \\
(-0.485,1.708)\end{array}$ & 0.272 \\
\hline Master's degree & 21 & $3.38(0.80)$ & $\begin{array}{c}-0.119 \\
(-1.197,0.959)\end{array}$ & 0.827 & $\begin{array}{c}0.502 \\
(-0.620,1.623)\end{array}$ & 0.377 \\
\hline $\begin{array}{l}\text { Doctorate } \\
\text { degree } \\
\text { Affiliation }\end{array}$ & 12 & $3.17(0.72)$ & $\begin{array}{c}-0.333 \\
(-1.446,0.779)\end{array}$ & 0.554 & $\begin{array}{c}0.434 \\
(-0.740,1.608)\end{array}$ & 0.466 \\
\hline $\begin{array}{l}\text { Nuclear power } \\
\text { generation }\end{array}$ & 58 & $3.68(0.75)$ & Reference & & & \\
\hline $\begin{array}{l}\text { Nuclear fuel } \\
\text { manufacturing }\end{array}$ & 10 & $3.60(0.70)$ & $\begin{array}{c}-0.090 \\
(-0.592,0.412)\end{array}$ & 0.724 & $\begin{array}{c}-0.09 \\
(-0.611,0.432)\end{array}$ & 0.734 \\
\hline $\begin{array}{l}\text { Large-scale } \\
\text { irradiation } \\
\text { facility }\end{array}$ & 2 & $3.50(0.71)$ & $\begin{array}{c}-0.190 \\
(-1.244,0.864)\end{array}$ & 0.722 & $\begin{array}{c}-0.057 \\
(-1.090,0.975)\end{array}$ & 0.913 \\
\hline $\begin{array}{c}\text { Radiation waste } \\
\text { disposal }\end{array}$ & 1 & 4.00 & $\begin{array}{c}0.310 \\
(-1.168,1.789)\end{array}$ & 0.679 & $\begin{array}{c}0.574 \\
(-0.863,2.012)\end{array}$ & 0.431 \\
\hline $\begin{array}{l}\text { Research and } \\
\text { development } \\
\text { institutions }\end{array}$ & 62 & $3.40(0.73)$ & $\begin{array}{l}-0.286 \\
(-0.554 \\
-0.019)\end{array}$ & 0.036 & $\begin{array}{c}-0.42 \\
(-0.855,0.015)\end{array}$ & 0.059 \\
\hline
\end{tabular}


Table 2. Cont.

\begin{tabular}{|c|c|c|c|c|c|c|}
\hline \multirow{2}{*}{ Factor } & \multirow{2}{*}{ Number } & \multirow{2}{*}{$\begin{array}{c}\text { Mean (SD) } \\
\text { of Response }\end{array}$} & \multicolumn{2}{|c|}{ Univariate } & \multicolumn{2}{|c|}{ Multivariate } \\
\hline & & & ${ }^{\Psi} \mathrm{B}(95 \% \mathrm{Cl})$ & $p$-Value & ${ }^{\Psi} \mathrm{B}(95 \% \mathrm{Cl})$ & $p$-Value \\
\hline \multicolumn{7}{|l|}{$\begin{array}{l}\text { Occupational } \\
\text { role }\end{array}$} \\
\hline $\begin{array}{l}\text { Licensee } \\
\text { worker }\end{array}$ & 92 & $3.67(0.73)$ & Reference & & & \\
\hline Inspector & 41 & $3.27(0.71)$ & $\begin{array}{l}-0.406 \\
(-0.674 \\
-0.137)\end{array}$ & $0.003 *$ & $\begin{array}{c}-0.356 \\
(-0.702 \\
-0.011)\end{array}$ & $0.043^{*}$ \\
\hline \multicolumn{7}{|c|}{ Period of career (years) } \\
\hline Less than 1 year & 13 & $3.23(0.93)$ & Reference & & & \\
\hline $1 \sim 5$ & 52 & $3.48(0.54)$ & $\begin{array}{c}0.25 \\
(-0.193,0.693)\end{array}$ & 0.267 & $\begin{array}{c}0.233 \\
(-0.224,0.689)\end{array}$ & 0.315 \\
\hline $6 \sim 10$ & 19 & $3.47(0.84)$ & $\begin{array}{c}0.243 \\
(-0.272,0.758)\end{array}$ & 0.352 & $\begin{array}{c}0.147 \\
(-0.375,0.668)\end{array}$ & 0.578 \\
\hline $11 \sim 15$ & 17 & $3.41(0.87)$ & $\begin{array}{c}0.181 \\
(-0.346,0.708)\end{array}$ & 0.498 & $\begin{array}{c}0.087 \\
(-0.456,0.630)\end{array}$ & 0.752 \\
\hline over 16 & 32 & $3.91(0.73)$ & $\begin{array}{c}0.675 \\
(0.205,1.146)\end{array}$ & $0.005 *$ & $\begin{array}{c}0.461 \\
(-0.023,0.945)\end{array}$ & 0.062 \\
\hline \multicolumn{7}{|c|}{ Job proportion in medical emergencies (percentage, \%) } \\
\hline Less than 20 & 77 & $\begin{array}{c}3.68 \\
(0.75)\end{array}$ & Reference & & & \\
\hline $21 \sim 40$ & 16 & $3.38(0.62)$ & $\begin{array}{c}-0.3 \\
(-0.694,0.093)\end{array}$ & 0.133 & $\begin{array}{c}0.036 \\
(-0.406,0.478)\end{array}$ & 0.872 \\
\hline $41 \sim 60$ & 10 & $\begin{array}{c}3.5 \\
(0.71)\end{array}$ & $\begin{array}{c}-0.175 \\
(-0.656,0.306)\end{array}$ & 0.472 & $\begin{array}{c}0.045 \\
(-0.462,0.552)\end{array}$ & 0.861 \\
\hline $61 \sim 80$ & 10 & $\begin{array}{c}2.9 \\
(0.88)\end{array}$ & $\begin{array}{l}-0.775 \\
(-1.256 \\
-0.294)\end{array}$ & $0.002 *$ & $\begin{array}{c}-0.345 \\
(-0.908,0.218)\end{array}$ & 0.227 \\
\hline $81 \sim 100$ & 20 & $3.55(0.60)$ & $\begin{array}{c}-0.125 \\
(-0.485,0.234)\end{array}$ & 0.491 & $\begin{array}{c}0.517 \\
(-0.028,1.062)\end{array}$ & 0.063 \\
\hline
\end{tabular}

${ }^{*} p<0.05 .{ }^{\Psi}$ Unstandardized coefficient in the linear regression analyses. Adjusting factors: sex, occupational role, career period, and job proportion in emergency medicine. All of the items were rated using a five-point Likert scale: 1 (entirely disagree) to 5 (entirely agree). CI: confidential interval; SD: standard deviation.

\subsection{Different Opinions on the Radiation Emergency Medicine System between Inspectors and} Licensee Workers

We compared the results of the other questions about radiation emergency medicine to explore whether occupational roles are associated with the survey response. All of the respondents assessed the radiation emergency medicine system as being at an above average level, including the safety laws, regulation policy, and emergency plan of institutes (Table 3). Interestingly, we observed some discrepancies in the surveyed responses between licensee workers and inspectors. Compared to inspectors, licensee workers favorably mentioned that the emergency medicine system for radiation accidents is well-prepared in all of the questions, especially on the governmental regulatory policy for radiation safety ( $p=0.007$ in Mann-Whitney U test). Furthermore, they also had different views on the important items of radiation emergency medicine (Figure 1). Licensee workers conceived that the workforce (34.1\%) is the most important factor in the emergency medicine system, unlike inspectors, who prioritized the laws and regulations for safety $(30 \%)$. Licensee workers perceived that the rescue activity $(42.7 \%)$ was the highest priority for the radiation emergency medical response. Still, communication with the emergency staff $(40.5 \%)$ was thought to be most critical by the inspectors. 
Table 3. Analysis of the surveyed responses for questions Q8 Q10 using Mann-Whitney U test.

\begin{tabular}{|c|c|c|c|c|c|c|c|c|c|c|}
\hline \multirow{3}{*}{ Survey Question } & \multirow{2}{*}{\multicolumn{3}{|c|}{ Total }} & \multicolumn{6}{|c|}{ Occupational Role } & \multirow{3}{*}{$\begin{array}{c}\text { Mann-Whitney U } \\
\text { Test ( } p \text {-Value) }\end{array}$} \\
\hline & & & & \multicolumn{3}{|c|}{ Licensee Worker } & \multicolumn{3}{|c|}{ Inspector } & \\
\hline & $\mathbf{N}$ & Mean & SD & $\mathbf{N}$ & Mean & SD & $\mathbf{N}$ & Mean & SD & \\
\hline $\begin{array}{l}\text { Q8. Do you agree that the national plan of } \\
\text { emergency medicine is well-prepared for } \\
\text { nuclear or radiation accidents? }\end{array}$ & 133 & 3.55 & 0.74 & 92 & 3.67 & 0.73 & 41 & 3.27 & 0.71 & 0.004 * \\
\hline $\begin{array}{l}\text { Q9. Do you think that the emergency } \\
\text { medicine system for radiation facilities is } \\
\text { reasonably regulated and enforced by } \\
\text { the law? }\end{array}$ & 133 & 3.53 & 0.71 & 92 & 3.59 & 0.74 & 41 & 3.41 & 0.63 & 0.205 \\
\hline $\begin{array}{l}\text { Q10. Do you think that the government's } \\
\text { regulation policy on the radiation industry } \\
\text { is appropriate? }\end{array}$ & 132 & 3.44 & 0.67 & 91 & 3.54 & 0.69 & 41 & 3.22 & 0.57 & $0.007^{*}$ \\
\hline $\begin{array}{l}\text { Q11. Do you agree that your institute's } \\
\text { emergency medicine system is effective } \\
\text { enough to protect the citizens from } \\
\text { radiation accidents? }\end{array}$ & 131 & 3.69 & 0.80 & 91 & 3.76 & 0.82 & 40 & 3.53 & 0.72 & 0.117 \\
\hline
\end{tabular}

$* p<0.05$. All of the items were rated using a five-point Likert scale: 1 (entirely disagree) to 5 (entirely agree). N: number, SD: standard deviation.

A

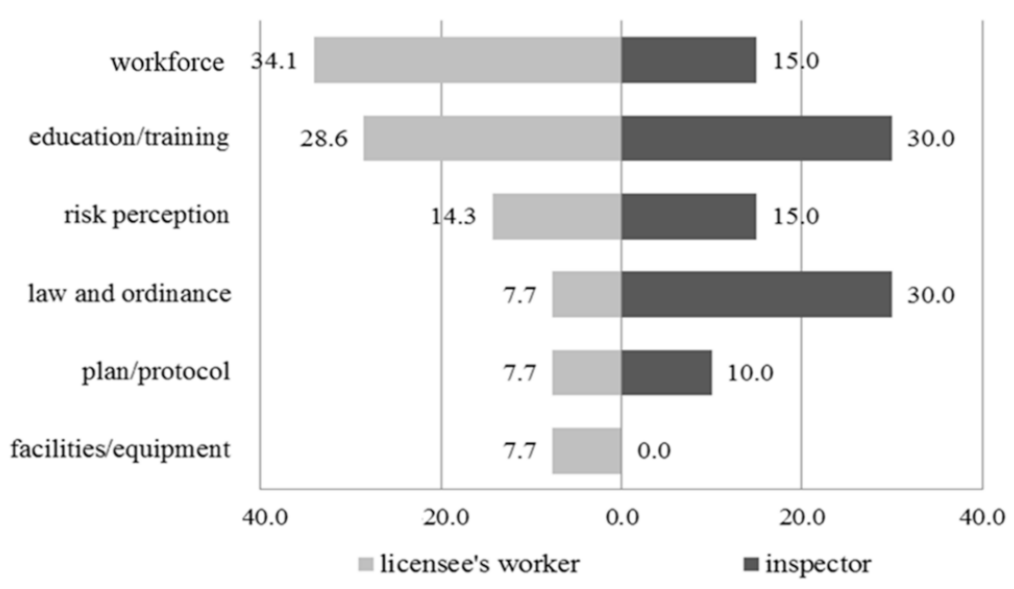

B

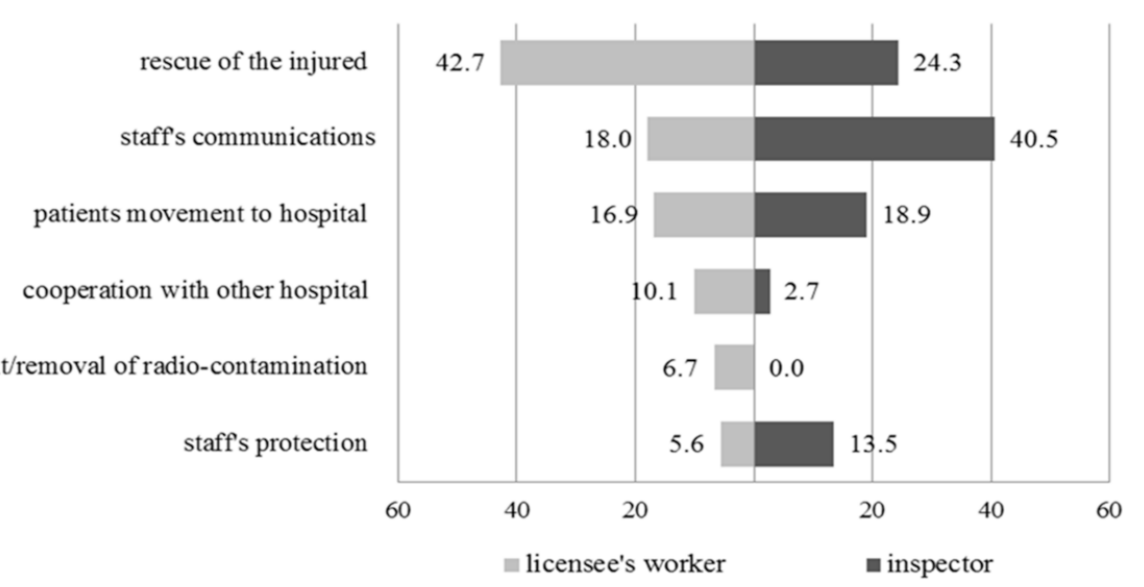

Figure 1. Comparison of opinions between licensee workers and inspectors. (A) Response to question 12 , "What is the most important aspect of the regulation of emergency medicine for radiation accident?"; (B) response to question 13, "What is the most important factor for an effective medical response in radiation emergency?". Workforce.

\section{Discussion}

Here, we found that the national radiation emergency medicine plan was found to be well prepared by both inspectors and licensee workers. This consensus could have resulted 
from a long period of investment and efforts in radiation safety due to the social anxiety of radiation exposure because of the Fukushima NPP accidents $[15,16]$. Interestingly, there was some discrepancy in the evaluation of radiation emergency medicine, although it was small. Compared to inspectors, licensee workers showed a more favorable assessment in several questions about emergency medicine. An in-depth analysis demonstrated that the job proportion related to emergency medicine could be a contributing factor to the responses of licensee workers (Table 1). They had a relatively small proportion of emergency medicine as part of their job profile. Notably, while most of them $(86.9 \%)$ had less than $40 \%$ of their work being relevant to radiation emergency preparedness, almost half of inspectors had over $80 \%$ of their job profile related to emergency medicine. This could imply that the facility workers' tasks related to emergency medicine in their companies/institutes are regarded as additional minor work, which may not be considered as serious. We could not determine whether the small work proportion related to radiation emergency medicine might be detrimental to the actual operations of plans in accidents without testing in radiation emergency situations. However, some evidence found in the exercise supported that their favorable evaluation is not good enough to make it complete. Radiation emergency medical plans have been used periodically and examined by inspectors in the exercise. The inspectors always find some insufficient parts of plans and recommend that they should be revised and complemented even though licensee workers highly evaluate their own plan. Our data apparently showed that people with a small proportion of radiation emergency work favorably estimated their preparedness for radiation accidents. Furthermore, these data could suggest that licensee workers exclusively charged with emergency medicine are needed for securing a more robust system of radiation safety.

The positive perception of the current status could be evidenced by the high evaluation of the emergency medical system of the companies/institutes (question \#11 in Table 3). This might be considered to be a result of complacency, as specialists believe the emergency plan is above average. Inspectors seemed to assess the emergency medical system more rigorously than licensee workers in all of the questions. They were strict in their evaluation of the government policy of safety regulation for the radiation industry even though their jobs were entrusted by the national authority, NSSC. This shows that their independent inspection activity could be guaranteed by the government, which is a basis for a fine and transparent regulatory system.

The survey results can be used to fill the perception gap between inspectors and licensee workers. As shown in Figure 1, inspectors usually examine the emergency medicine plan based on the legal regulations, which was evaluated with very low priority in the emergency response system by the licensee workers. Instead, licensee workers considered that personnel responsible for emergency medicine was highly necessary for radiation safety. In addition, inspectors perceived the communication between the emergency staff as the most important in medical radiation responses. Communication could contribute to the safety of the staff, which is a primary concern in all emergency response situations [17]. Overall, the inspectors' views seem to focus on the efficient and sustainable response of emergency medicine at the systemic level. The different perspectives between inspectors and licensee workers stem from the actual properties of each occupational role in the regulatory system for radiation medical emergencies. To reduce this perception gap between inspectors and licensee workers in the regulatory system for radiation medical emergencies, regular technical workshops and intra- or inter-social meetings are strongly recommended to increase their understanding of differences in perception of the regulatory system, as well as to exchange information on important aspects of it. Additionally, from a regulatory point of view, governmental or institutional regulators should analyze the contributing factors of the perception of licensee workers on radiation emergency medicine and consider whether the factors should be reflected in actual laws or discipline. In addition, the Cabinet Office and Nuclear Regulation Authority are responsible for protection against nuclear disasters and enforce the various regulations at on-site and off-site locations, based on 
lessons learned from the 2011 Fukushima Daiichi NPP accident in Japan [18]. The importance of REM reconstruction and the information about the REM system in Japan after the Fukushima NPP accident would strengthen the importance of this study [6].

There were some limitations to our study. First, all of the inspectors were affiliated with one organization, NREMC. Considering the expertise in radiation emergency medicine, NSSC (Korean government) has entrusted NREMC with the role and responsibilities regarding the examination of the emergency plans. This could produce the perception gap in the evaluation of the licensee emergency plans for radiation accidents, even if the independent assessment is guaranteed, as mentioned above. Expansion of inspectors to other independent institutes may lead to different assessment results. Second, our survey data explained that the current level of national plans in radiation emergency medicine was estimated to be above average without a comparison of previous survey data immediately after the construction of the regulatory system. In other words, this kind of study should be performed repeatedly every two or three years to get more valuable information to produce a well-made emergency plan, regarding communication between inspectors and workers.

\section{Conclusions}

Based on our survey, we showed differences in opinions of inspectors and licensee workers in the assessment of an emergency medicine system for radiation accidents. Different views seem to come from the actual properties of each occupational role for the regulatory system. It is not easy to determine which one is more important in radiation emergency medicine. Both inspectors and licensee workers should recognize their different perceptions and exchange ideas to find a reasonable and consensual way to improve the regulatory system for radiation emergency medicine. To accomplish the accurate judgment on the emergency medical plan, a regular survey should be implemented and analyzed periodically.

Author Contributions: Conceptualization, K.M.S., E.L., and M.Y.; methodology, Y.L. and E.L.; validation, Y.Y.C. and K.M.S.; formal analysis, Y.Y.C. and Y.L.; investigation, Y.Y.C. and M.Y.; resources, M.Y.; data curation, E.L.; writing —original draft preparation, K.M.S. and Y.Y.C.; writing—review and editing, Y.Y.C. and M.Y.; visualization, Y.Y.C.; supervision, K.M.S.; project administration, K.M.S. and Y.W.J.; funding acquisition, Y.W.J. All authors have read and agreed to the published version of the manuscript.

Funding: This study was supported by the 50091-2020 grant from the NSSC, Republic of Korea. The funder had no role in the study design, data collection and analysis, the decision to publish, and preparation of the manuscript.

Institutional Review Board Statement: The study was conducted according to the guidelines of the Declaration of Helsinki, and approved by the Institutional Review Board (IRB: KIRAMS 2020-04-009) of the Korea Institute of Radiological \& Medical Sciences.

Informed Consent Statement: Informed consent was obtained from all subjects involved in the study.

Data Availability Statement: The data presented in this study are available in Assessment of an Emergency Medicine System for Radiation Accidents in Korea: A State Survey of the Workers Involved the Medical Response to Radiation Accidents.

Conflicts of Interest: The authors declare no conflict of interest.

\section{Appendix A A Survey on the Perception of Emergency Medicine for Radiation Accidents}

Due to the social requirement for a consolidated system of emergency medicine for radiation accidents after the Fukushima disaster, the Nuclear Safety and Security Commission has regulated radiation facilities through the revision and inspection of licensee's own emergency plan. The survey data will be utilized for filling the perception gap between inspectors and licensee's workers, who are involved in the plan construction 
of emergency medicine. This survey could contribute to the proper implementation of the medical emergency system under a radiation crisis.

1. What is your sex?

(1) male (2) female

2. What is your age?

(1) 20-29 years (2) 30-39 years (3) 40-49 years (4) 50-69 years

3. What is your degree?

(1) high school graduation (2) bachelor's degree (3) master's degree (4) doctorate degree

4. What is your affiliation?

(1) NPP Co. (2) Nuclear fuel manufacturing Co. (3) Large-scale irradiation facility

(4) Radio-waste disposal Co. (5) R\&D institute

5 . What is your role in the radiation emergency medicine plan?

(1) licensee's worker (2) inspector

6. For how long have you been working in a field related to radiation emergency?

(1) less than 1 year (2) 1 5 years (3) 6 10 years (4) 11 15 years (5) more than 16 years

7. What is the proportion of work related to radiation emergency medicine in your job?

(1) less than $20 \%$ (2) $21 \sim 40 \%$ (3) $41 \sim 60 \%$ (4) $61 \sim 80 \%$ (5) $81 \sim 100 \%$

8. Do you agree that the national plan of emergency medicine is well-prepared for nuclear or radiation accidents?

(1) entirely disagree (2) disagree (3) neutral (4) agree (5) entirely agree

9. Do you think that the emergency medicine system for radiation facilities is reasonably regulated by the law and enforcement?

(1) entirely disagree (2) disagree (3) neutral (4) agree (5) entirely agree

10. Do you think that the government's regulation policy on the radiation industry is appropriate?

(1) entirely disagree (2) disagree (3) neutral (4) agree (5) entirely agree

11. Do you agree that your institute's emergency medicine system is effective enough to protect its workers from radiation accidents?

(1) entirely disagree (2) disagree (3) neutral (4) agree (5) entirely agree

12. What is the most important aspect of the regulation of emergency medicine for radiation accident?

(1) law and enforcement (2) workforce (3) facilities/equipment

(4) education/training (5) plan/protocol (6) risk perception

13. What is the most important factor for the effective medical response in radiation emergency?

(1) rescue of the injured (2) measurement/removal of radio-contamination (3) transfer of patients to hospital

(4) cooperation with other hospital (5) staffs protection (6) communications of staffs

14. Do you know that we are living around radiation from the nature, including soil, tree, food, and cosmic rays?

(1) yes (2) no

15. Which one is more detrimental to human health if the radiation level is same, artificial radiation or natural radiation?

(1) artificial radiation (2) natural radiation (3) both same

16. Which ray has the greatest penetrating power?

(1) alpha (2) beta (3) gamma (4) all the same

17. What level is the average dose limit of five years for radiation workers?

(1) $10 \mathrm{mSv}$ (2) $20 \mathrm{mSv}$ (3) $50 \mathrm{mSv}$ (4) $100 \mathrm{mSv}$ (5) $200 \mathrm{mSv}$

18. What is the approximate dose of decreasing the number of lymphocytes after radiation exposure to the whole body?

(1) $50 \mathrm{mSv}$ (2) $100 \mathrm{mSv}$ (3) $500 \mathrm{mSv}$ (4) $1000 \mathrm{mSv}$ (5) $2000 \mathrm{mSv}$

\section{References}

1. Seong, K.M.; Kwon, T.; Seo, S.; Lee, D.; Park, S.; Jin, Y.W.; Lee, S.S. Perception of low dose radiation risks among radiation researchers in Korea. PLoS ONE 2017, 12, e0171777. 
2. Park, B.J. Analysis of public perception on radiation: With one year after Fukushima nuclear accident. J. Radiat. Prot. Res. 2012, 37, 1-9. [CrossRef]

3. Kim, Y. The Radiation Problem and Its Solution from a Health Communication Perspective. J. Korean Med. Sci. 2016, 31, S88-S98. [CrossRef] [PubMed]

4. Jones, C.G. The US Nuclear Regulatory Commission radiation protection policy and opportunities for the future. J. Radiol. Prot. 2019, 39, R51-R62. [CrossRef] [PubMed]

5. Cho, M.; Seong, K.M.; Park, C.Y.; Bae, G.R.; Kim, S.; Jin, Y.W. Sustainable medical preparedness and response system for radiation emergencies in the republic of Korea. Radiat. Prot. Dosim. 2018, 182, 20-24. [CrossRef] [PubMed]

6. Ojino, M.; Ishii, M. Reconstruction of the Radiation Emergency Medical System from the Acute to the Sub-acute Phases after the Fukushima Nuclear Power Plant Crisis. Jpn. Med. Assoc. J. 2014, 57, 40-48.

7. International Atomic Energy Agency. Preparedness and Response for a Nuclear or Radiological Emergency; (General Safety Requirements) IAEA Safety Standards Series No. GSR Part 7; IAEA: Vienna, Austria, 2015; ISSN 1020-525X. Available online: http:/ / www.iaea.org/books (accessed on 3 February 2020).

8. Murray, B.P.; Kim, E.; Ralston, S.A.; Moran, T.P.; Iddins, C.; Kazzi, Z. Radiation Emergency Readiness among US Medical Toxicologists: A Survey. Disaster Med. Public Health Prep. 2020, 20, 1-6. [CrossRef] [PubMed]

9. International Atomic Energy Agency. IEAE-TECDOC-1162, Generic Procedures for Assessment and Response during a Radiological Emergency; Emended Version; IAEA: Vienna, Austria, 2013; ISSN 1011-4289. Available online: www.pub.iaea/books/ (accessed on 3 February 2020).

10. Coleman, C.N.; Lurie, N. Emergency medical preparedness for radiological/nuclear incidents in the United States. J. Radiol. Prot. 2012, 32, N27-N32. [CrossRef]

11. Sjöberg, L. Risk Perception: Experts and the Public. European Psychologist. Eur. Psychol. 1998, 3, 1-12. [CrossRef]

12. Tanja, P. Radiation risk perception: A discrepancy between the experts and the general population. J. Environ. Radioact. 2014, 133, 86-91.

13. Takebayashi, Y.; Lyamzina, Y.; Suzuki, Y.; Murakami, M. Risk Perception and Anxiety Regarding Radiation after the 2011 Fukushima Nuclear Power Plant Accident: A Systematic Qualitative Review. Int. J. Environ. Res. Public Health. 2017, 14, 1306. [CrossRef]

14. Murakami, M.; Takebayashi, Y.; Takeda, Y.; Sato, A.; Igarashi, Y.; Sano, K.; Yasutaka, T.; Naito, W.; Hirota, S.; Goto, A.; et al. Effect of Radiological Countermeasures on Subjective Well-Being and Radiation Anxiety after the 2011 Disaster: The Fukushima Health Management Survey. Int. J. Environ. Res. Public Health 2018, 15, 124. [CrossRef]

15. Park, J. The social construction of risk perception: A comparison between risk perceptions of nuclear power plants after the Chernobyl and the Fukushima nuclear accident. Environ. Philos. 2013, 15, 117-143.

16. Jin, S. An analysis on Koreans' perception types of nuclear power after the Fukushima accident. Korean Public Adm. Q. 2012, 24, 1011-1038.

17. Abaza, A. Assessment of Radiation Emergency Preparedness in Nuclear Medicine. Swift. J. Med. Med. Sci. 2016, 2, 39-44.

18. Tsujiguchi, T.; Sakamoto, M.; Koiwa, T.; Suzuki, Y.; Ogura, K.; Ito, K.; Yamanouchi, K.; Kashiwakura, I.A. Simple Survey of the Preparation Situation for Resident's Evacuation in Japanese Prefectures After the Fukushima Daiichi Nuclear Power Plant Accident. Front. Public Health 2020, 2, 496716. [CrossRef] 